NOTA DE PESQUISA

\title{
DETECÇÃO DE ANTICORPOS PARA ANAPLASMA SP. EM PEQUENOS RUMINANTES NO SEMI-ÁRIDO DO ESTADO DE PERNAMBUCO, BRASIL
}

\author{
RAFAEL A. N. RAMOS'; CARLOS A. N. RAMOS²; FLÁBIO R. ARAÚJO3; ELAINE S. P. MELO²; \\ ANTÔNIO A. S. M. TEMBUE'; MARIAA. G. FAUSTINO ${ }^{5}$; LEUCIO C. ALVES ${ }^{5}$; GRÁCIA M. S. ROSINHA ${ }^{3}$; \\ CARINA ELISEI ${ }^{6}$; CLEBER O. SOARES ${ }^{3}$
}

\begin{abstract}
RAMOS, R.A.N.; RAMOS, C.A.N.; ARAÚJO, F.R.; MELO, E.S.P.; TEMBUE, A.A.S.M.; FAUSTINO, M.A. G.; ALVES, L.C.; ROSINHA, G.M.S.; ELISEI, C.; SOARES, C.O. [Detection of antibodies against Anaplasma sp. in small ruminants from the semi-arid region against Pernambuco State, Brazil]. Detecção de anticorpos para Anaplasma sp. em pequenos ruminantes no semi-árido do Estado de Pernambuco, Brasil. Revista Brasileira de Parasitologia Veterinária, v. 17, n. 2, p. 115-117, 2008. Embrapa Gado de Corte, Br 262, Km 04, CP 154, Campo Grande, MS 79002-970, Brasil. E-mail: flabio@cnpgc.embrapa.br

This paper reports the detection of antibodies against Anaplasma sp. in goats and sheep from the semi-arid region from Pernambuco State, Brazil, using an enzyme-linked immunosorbent assay with recombinant MSP5 of Anaplasma marginale. Sera from 243 goats and 68 sheep from Ibimirim municipality were analyzed and frequencies of antibodies of $11.93 \%(29 / 243)$ and $16.17 \%(11 / 68)$ were found for goats and sheep, respectively. The epidemiological relevance of the findings was discussed.
\end{abstract}

KEY WORDS: anaplasmosis, goat, sheep, ELISA, recombinant MSP5.

\section{RESUMO}

Neste trabalho é descrita a deteç̧ão de anticorpos para Anaplasma sp. em caprinos e ovinos da região do semi-árido do Estado de Pernambuco, Brasil, utilizando-se um ensaio de imunoadsorção enzimática baseado em MSP5 recombinante de Anaplasma marginale. Foram analisados soros de 243 caprinos e 68 ovinos provenientes do município de Ibimirim, e observadas freqüências de anticorpos de $11,93 \%(29 / 243)$ e $16,17 \%(11 / 68)$ para caprinos e ovinos, respectivamente. A importância epidemiológica dos achados foi discutida.

\footnotetext{
${ }^{1}$ Curso de Medicina Veterinária, Universidade Federal Rural de Pernambuco (UFRPE), Rua Dom Manoel de Medeiros, s/n, Dois Irmãos, Recife, PE 52171-900, Brasil.

${ }^{2}$ Mestrado em Ciência Animal, Universidade Federal de Mato Groso do Sul (UFMS), Campo Grande, MS, Brasil.

${ }^{3}$ Embrapa Gado de Corte, BR 262. Km 04, CP 154, Campo Grande, MS 79002-970. E-mail: flabio@cnpgc.embrapa.br

${ }^{4}$ Mestrado em Ciências Veterinárias, UFRPE, Recife, Brasil.

${ }^{5}$ Departamento de Medicina Veterinária, UFRPE, Recife, PE, Brasil.

${ }^{6}$ Bolsista DCR Cnpq/FUNDECT/Embrapa Gado de Corte, Campo Grande, MS, Brasil.
}

PALAVRAS-CHAVE: Anaplasmose, caprino, ovino, ELISA, MSP5 recombinante.

Anaplasma sp. é uma bactéria intracelular obrigatória que infecta bovinos (Anaplasma marginale, A. centrale e A. bovis) e pequenos ruminantes (A. ovis) (KUTTLER et al., 1984). O gênero Anaplasma pertence a ordem Rickettsiales, família Anaplasmataceae (DUMLER et al., 2001). Recentemente, Dumler et al. (2001) propuseram a reorganização da ordem Rickettsiales e foram incluídos ao gênero Anaplasma algumas espécies do gênero Ehrlichia. Desta forma, passaram a ser incluídas ao gênero Anaplasma as espécies: A. phagocytophilum, que infecta e causa doença em uma grande variedade de hospedeiros (humanos, caninos, bovinos, eqüídeos e pequenos ruminantes) e $A$. bovis, recentemente, descrita infectando bovinos na microrregião de Campos dos Goytacazes, Estado do Rio de Janeiro, Brasil (SANTOS; CARVALHO, 2006).

A distribuição das espécies de Anaplasma que infectam pequenos ruminantes, principalmente $A$. ovis, tem sido relatada em vários países da Europa (HORNOK et al., 2007), África, Estados Unidos (NDUNG'U et al., 1995) e Ásia (LIU et 
al., 2005). No entanto, nos países da América do Sul, dentre os quais o Brasil, a ocorrência de anaplasmose em pequenos ruminantes são escassos (MOTA et al., 1996).

Pesquisas sobre as proteínas de membrana externa de Anaplasma sp. têm possibilitado o desenvolvimento de ensaios de imunoadsorção enzimática (ELISA), baseados em proteínas recombinantes de A. marginale (ARAÚJO et al., 2005), dentre as quais MSP5 (SILVA et al., 2006). Essas pesquisas têm oferecido também uma grande gama de informações sobre a conservação dessas proteínas no gênero (DREHER et al., 2005; STRIK et al., 2007), inclusive com reações sorológicas cruzadas descritas entre MSP5 de A. marginale, A. centrale, A. phagocytophilum e A. ovis (DREHER et al., 2005), e entre MSP5 de A. phagocytophilum e A. platys, Ehrlichia canis e E. chaffeensis (STRIK et al., 2007).

Com o objetivo de pesquisar anticorpos para Anaplasma sp. em caprinos e ovinos da região do semi-árido do Estado de Pernambuco, foram obtidas amostras de soro de 243 caprinos e 68 ovinos provenientes do município de Ibimirim.

A detecção dos anticorpos foi realizada utilizando-se um ensaio de ELISA, baseado em MSP5 recombinante de A. marginale (MELO, 2006), adaptado para ovinos e caprinos. Para isto, foram utilizadas microplacas Greiner Bio One (Microlon, 655101), e as diluições ótimas de antígeno, soros, conjugado e tampões, assim como o tempo de parada da reação foi avaliado testando-se três soros pré-imunes e três soros imunes provenientes de dois ovinos e um caprino. Os animais, clinicamente saudáveis foram inoculados três vezes por via subcutânea, com aproximadamente $1 \mu \mathrm{g}$ de lisado de corpúsculo inicial de A. marginale (isolado Pernambuco - Zona da Mata) com intervalos de sete dias. A primeira inoculação foi realizada com o adjuvante MPL + TDM + CWS (Sigma, M-6661) conforme instruções do fabricante, e as inoculações subseqüentes foram feitas com adjuvante incompleto de Freund (Sigma, F-5506) também conforme instruções do fabricante.

O protocolo de inoculação utilizado mostrou-se eficaz na produção de anti-soro específico de caprino e ovino contra MSP5 de A. marginale. Os soros imunes dos ovinos apresentaram densidades ópticas médias 2,6 a 5,5 vezes superiores aos respectivos soros pré-imunes. Com relação ao caprino, a densidade óptica do soro imune superou em apenas duas vezes a do soro pré-imune. Isso representa uma alternativa para o desenvolvimento de anti-soro específico de caprino e ovino, para utilização como controles em ensaios sorológicos, em regiões nas quais não se dispõe de soros de animais reconhecidamente infectados.

Com relação à freqüência de anticorpos dos caprinos e ovinos avaliados, $11,93 \%$ (29/243) e 16,17\% (11/68), respectivamente, apresentaram anticorpos para MSP5. Esses resultados foram inferiores aos encontrados por Ndung'u et al. (1995) em regiões da África, aos encontrados por Razmi et al. (2006) no Iran (80,30\% em caprinos, $47,53 \%$ em ovinos) e Hornok et al. (2007) na Hungria (99,40\% em ovinos).
A possível explicação para a baixa freqüência de anticorpos encontrada pode estar relacionada às condições climáticas adversas da região e sua influência sobre a biologia reprodutiva dos carrapatos vetores (KESSLER; SCHENK, 1998). Apesar disso, esses resultados são relevantes sob dois aspectos principais: i) por ser o primeiro relato sobre a detecção de anticorpos para MSP5 de A. marginale em caprinos e ovinos no Brasil; ii) e a presença desses anticorpos sugere que algumas espécies de Anaplasma e/ou de Ehrlichia que infectam pequenos ruminantes estão presentes na região.

Atualmente, reconhece-se que, devido à conservação da proteína MSP5 na família Anaplasmataceae, os ensaios sorológicos que utilizam essa proteína como antígeno não são capazes de distinguir infecções causadas por Anaplasma sp. ou Ehrlichia sp., principalmente se utilizados para animais passíveis de infecção por mais de uma espécie (DREHER et al., 2005). No entanto, representam importantes ferramentas de triagem para detecção das infecções por Anaplasma/Ehrlichia em diversos hospedeiros (STRIK et al., 2007).

Estudos futuros utilizando ferramentas moleculares são necessários para especificar quais agentes (Anaplasma/ Ehrlichia) induziram a formação de anticorpos para MSP5 nos caprinos e ovinos da região do semi-árido pernambucano. Os resultados apresentados demonstram indício da presença de A. ovis e/ou A. phagocytophilum, infectando caprinos e ovinos, no território nacional.

\section{REFERÊNCIAS BIBLIOGRÁFICAS}

ARAÚJO, F. R.; MELO, V. S. P.; RAMOS, C. A. N.; MADRUGA, C. R.; SOARES, C. O.; KESSLER, R. H.; ALMEIDA, N. F.; ARAÚJO, G. S.; TORRES, R. A. A. JR.; FRAGOSO, S. P.; ARAUCO, P. R. C.; BACANELLI, G.; OLIVEIRA, M. B; SANTOS, L. R. Development of enzyme-linked immunoadsorbent assays based on recombinant MSP1a and MSP2 of Anaplasma marginale. Memórias do Instituto Oswaldo Cruz, v. 100, n. 7, p. 765769, 2005.

DREHER, U. M.; DE LA FUENTE, J.; HOFMAMLEHMANN, R.; MELI, M. L.; PUSTERLA, N.; KOCAN, K. M.; WOLDEHIWET, Z.; BRAUN, U.; REGULA, G.; STRAERK, K. D. C.; LUTZ, H. Serologic cross-reactivity between Anaplasma marginale and Anaplasma phagocytophilum. Clinical Diagnostic Laboratory Immunology, v. 2, n. 10, p. 1177-1183, 2005.

DUMLER, J. S.; BARBET, A. F.; BEKKER, C. P. J.; DASCH, G. A.; PALMER, G. H.; RAY, S. C.; RIKIHISA, Y; RURANGIRWA, F. R. Reorganization of genera in the families Rickettsiaceae and Anaplasmataceae in the order Rickettsiales: unification of some species of Ehrlichia with Anaplasma, Cowdria with Ehrlichia and Ehrlichia with Neorickettsia, descriptions of six new species combinations and designation of Ehrlichia equi and HE agent as subjective synonyms of Ehrlichia phagocytophila. International Journal of Systematic Evolution Microbiology, v. 51, n. 6, p. 2145-2165, 2001. 
KESSLER, R. H.; SCHENK, M. A. M. Carrapato, tristeza parasitária e tripanossomose dos bovinos. Campo Grande, MS: Embrapa Gado de Corte, 1998. 157 p.

KUTTLER, K. L. Anaplasma infection in wild and domestic ruminants: a review. Journal Wildlife Disease, v. 20, n. 1, p. 12-20, 1984.

HORNOK, S.; ELEK, V.; DE LA FUENTE, J.; NARANJO, V.; FARKAS, R.; MAJOROS, G.; FOLDVÁRI, G. First serological and molecular evidence on the endemicity of Anaplasma ovis and A. marginale in Hungary. Veterinary Microbiology, v. 122, n. 3-4, p. 316-322, 2007.

LIU, Z; LUO, J; BAI, Q; MA, M; GUAN, G; YIN, H. Amplification of 16S rRNA genes of anaplasma species in china for phylogenetics analysis. Veterinary Microbiology, v. 107, n. 1-2, p. 145-148, 2005.

MELO, E. S. P. Ensaio de imunoadsorção enzimática com MSP5 recombinante truncada para a detecção de anticorpos contra Anaplasma marginale em bovinos, 2006. 54 f. Dissertação (Mestrado) - Faculdade de Medicina Veterinária e Zootecnia. Universidade Federal de Mato Grosso do Sul, Campo Grande, MS, 2006.

MOTA, R. A.; SOARES, P. C.; SILVA, F. F.; SOARES, C. O.; LOPES, C. W. G.; MASSARD, C. L. Babesiose e anaplasmose caprina no estado de Pernambuco. In: CONGRESSO PANAMERICANO DE CIÊNCIA VETERINÁRIA, 15., 1996, Campo Grande, Resumos ... [Campo Grande]: Associação Panamericana de Ciências Veterinárias, 1996. p. 302.

NDUNG'U, L. W.; AGUIRRE, C.; RURANGIRWA, F. R.; MCELWAIN, T. F.; McGUIRE, T. C.; KNOWLES, D.;
PALMER, G. H. Detection of Anaplasma ovis infection in goats by major surface protein 5 competitive inhibition enzyme-linked immunosorbent assay. Journal Clinical Microbiology, v. 33, n. 3, p. 675-679, 1995.

RAZMI, G. R.; DASTJERDI, K.; HOSSIENI, H.; NAGHIBI, A.; BARATI, F.; ASLANI, M. R. An epidemiological study on Anaplasma infection in cattle, sheep, and goats in Mashhad suburb, Khorasan Province, Iran. Annals of the New York Academy Science, v. 1078, p. 479-781, 2006.

SANTOS, C. F.; CARVALHO, C. B. Primeiro relato de Anaplasma bovis (Donatien e Lestoquard, 1936) Dumler et al. (2001) na microrregião de Campos dos Goytacazes, Estado do Rio de Janeiro, Brasil. Revista Brasileira de Parasitologia Veterinária, v. 15, n. 3, p. 126-127, 2006.

SILVA, V. M. G.; ARAÚJO, F. R.; MADRUGA, C. R. M.; SOARES, C. O.; KESSLER, R. H.; ALMEIDA, M. A. O.; FRAGOSO, S. P.; SANTOS, L. R.; RAMOS, C. A. N.; BACANELLI, G.; TORRES JÚNIOR, R. A. A. Comparison between indirect enzyme-linked immunosorbent assays for Anaplasma marginale antibodies with recombinant major surface protein 5 and initial body antigens. Memórias do Instituto Oswaldo Cruz, v. 101, n. 5, p. 511-516, 2006.

STRIK, N. I.; ALLEMAN, A. R.; BARBET, A. F.; SORENSON, H. L.; WAMSLEY, H. L.; GASCHEN, F. P.; LUCKSCHANDER, N.; WONG, S.; CHU, F.; FOLEY, J. E.; BJOERSDORFF, A.; STUEN, S. Characterization of Anaplasma phagocytophilum major surface proteins 5 and the extent of its cross-reactivity with A. marginale. Clinical Vaccine Immunology, v. 14, n. 3, p. 262-268, 2007.

Recebido em 27 de setembro de 2007.

Aceito para publicação em 09 de abril de 2008. 